\title{
ATTORNEY PERSONALITIES AND SOME PSYCHOLOGICAL ASPECTS OF LEGAL CONSULTATION *
}

\section{ROBERT S. REDMOUNT $\dagger$}

Amidst the clap and thunder of authoritative rules, decisions, and precedents, the vital thoughts, operations, and decisions of attorneys suffer by comparison. It is they, as much as the courts and legislatures, who voice legal policy and direct the resolve, the reputation, and the power of law. In their consultative functions with clients, attorneys affect more persons directly, and with greater individual consequence, than do statute law and court decisions. They are the interpreters of the law-and its masters as well, insofar as they direct the uses to which it is to be put.

In practice, it is the attorney who specifically acquaints the public with the law prior to the courts and sometimes prior to the legislature. This is done through his law office counseling, his bargaining and conciliation in dealing with conflict, and his choice of strategy in contemplating litigation or some other formal procedure of intervention and decision.

Characteristically, differences in the advice given to clients and in the handling of cases are ascribed to differences in attorneys' skills. Some attorneys develop facts more assiduously and imaginatively. Some are more resourceful and even creative in devising the theory necessary to make a client's case viable in the contexts of law. It is the accommodation of such attorney skill and client circumstance that seems to determine the outcome, or at least the direction, of the client's problem situation.

One can fairly deduce that different attorneys might handle a given situation in different ways. The familiar implication is that the attorney's appraisal of the situation, his advice, and his strategy result from the synthesis of the empirical facts and professional theories known to him. Take a matter of tort, for instance. There is injury

* The author wishes to acknowledge the benefit and influence of a constant exchange of communication with Louis M. Brown, Esq., of Beverly Hills, California. $\mathrm{Mr}$. Brown has espoused the cause of what he and others have termed "preventive law" in both writing and teaching for more than a decade. His principal interest is in the handling of matters by legal counsel prior to and in avoidance of litigation.

t A.B. 1943, M.S. 1947, Pennsylvania State University; Ph.D. 1949, New York University; LL.B. 1957, Yale University; Member, Connecticut Bar; Certified Psychologist, State of New York. 
to a person and an attorney will prospectively represent this individual in a plaintiff's cause. He will decide what he knows about the circumstances of the accident. He will sift the facts and opinions given him by witnesses to establish "cause" in a layman's sense. Then he will endeavor to assimilate these to one or more theories of legal causation. He will use observable evidence and personal and expert opinions as to damages; and he can consider personal, business, and social consequences for his client. These he will relate to the legal remedies that might be available. He can cast a large net in search for witnesses to fortify his thought and strategy, and then contemplate how they and their testimony would weather the rigors of legal procedure.

Except in the clearest instances, where facts are so indelible and incontrovertible as to override any choice in policy, the attorney is left to decide his tactics, both with his client and with his adversary. He may seek to induce his client to take demanding action, conciliatory action, or no action at all. He may inspire his client to more or less militancy. He may stress the opportunity, or lack of it, for economic gain or recoupment. Or he may argue the virtues of personal and moral integrity. He may counsel his client to conciliatory behavior, whether from personal conviction and disposition or because of crass or stern professional judgments about the client's situation. He may handle his adversary contentiously, with tact and consideration, with contempt, or with fear. He may be amiable toward him, or hostile and suspicious. $\mathrm{He}$ is, withal, a tactician, but one whose dispositions and judgments must reveal something of the predominating personality that lies within.

It is curious that the impact of the attorney's personality is ignored in the common view of legal service. Perhaps it is not for lack of respect that this is so, but because "personality" seems an elusive matter with which to deal in any large, systematic sense.

\section{The Nature of Personality}

It is not intended here that the attorney be conceived as somehow unique in personality. The notion of a distinct characterization of individuals based upon professional identity has been mostly unrewarding. Anyhow, the attorney, in what he becomes, is ubiquitous to society and probably runs the gamut of possibility. However, it does appear that elements of personality commonplace to all are organized, handled, and accentuated in some particular ways. In the legal context, these are manifest in systematic differences in the behavior of attorneys and in vital distinctions in the character and direction of 
legal consultation. There is, further, a possibility of a wedding between the individual attorney, with his private heritage of experience, and particular psychological molds available in legal traditions, procedures, and resolutions to problems. ${ }^{1}$ The principal burden of what follows in this article is to elaborate these theses.

"Personality" is a concept used to describe some characteristic ways in which a being behaves. It implies some essential dispositions that persevere over a period of time in the being in many or most circumstances. Specifically, for man it is his particular mode or modes of adaptation to his environment. In principle, there is a cohering network of environments: biological, psychological, and social. Here we are concerned only with adaptation to social environment but must recognize that there are counterparts for what we say in the biological and psychological frameworks.

In the most essential and abstract terms three elements are involved in adaptation to social reality. There is the matter of coping with the physical universe and the social structures within it. One must come to some kind of terms with nature and with the organized traditions and expectations of society. Second is the matter of relations between persons. One must establish some degree and quality of contact with others. Third is a concern for a sense of self. One must discover and promote a balance of adjustment that establishes some kind of identity in life. In practice, these are commingled matters, but it is critically important to perceive each one distinctly.

\section{Position, Possession, and Coping Behavior}

Physical and social reality preexist the individual and require that he find his place and part. In advanced societies, this is identified as a matter of developing power and possession. There is emphasis upon learning and acquisition of many kinds, to the end that the individual may learn to control and manipulate his environment-or at least his responsibility in it-more effectively. In practical terms, this means

1 Attorney personality and its relation to the operation of law has rarely been the subject of scholarly concern. Contemplating mostly judge-made law and the process of litigation, the late Jerome Frank had a good deal of ascerbic comment about the impact of attorney personality. Opportunely using tenets from Freudian psychology, but without accepting or developing any systematic personality framework, Judge Frank noted the attorney's delusive "quest for certainty," his continuing dependency on a kind of paternal authority, and his childish conception of words as magic. These, in his view, have contributed to and supported a largely inflexible, overly-absolute, and insensitive process of judicial decision making. See FRANK, LAw AND THE MODERN MIND, 57-92, 243-52 (1930). The author has also made some comments on the relation of one dimension of personality, psychological and social dependency, to a variety of legal processes. See Redmount, Psychological Viezes in Jurisprudential Theories, 107 U. PA. L. REV. 472, 503-13 (1959). 
possessing knowledge to control or at least to contain natural elements. It means possessing wealth in various forms so as to guarantee freedom and security in a politically and socially confining system marked by laws and customs. It means possessing status as an instrument of influence and survival in a society that is contingent on the regulation of men.

The keynote for the individual, whether one refers to knowledge, wealth, or status, is possession and control. He develops coping behavior and is concerned about acquisition and possession. His behavior may be characterized by its grasping and demanding qualities, its competitiveness and retentiveness, its "dominatingness," ambition, and resistance.

For most attorneys, as for much of modern western society, the coping attitude is disproportionate. It is perhaps the largest single aspect of their personal and professional behavior. It is practically "legal instinct" to address most matters in terms of some kind of possession or benefit, and to aspire to some advantage in and over situations. In the principal aspects of a legal practice, the attorney struggles to advance or preserve property rights, to multiply or sustain economic benefits, or to facilitate economic and political power. A corporate or taxation practice, an emphasis on property and contractual matters, indicate a preoccupation with acquisitive matters.

Colloquially, it may be said that the attorney "comes naturally" by these dispositions. His personal history may be full of a need for possession of various kinds. He may demand sustenance, jealously guard material possessions, seek to dominate, resist efforts to subjugate him, curry status, and the like. These are some of the characteristics of an individual's growth process. Coping attitudes may become exaggerated in importance and reinforced if they have become contentious matters or sources of undue frustration in personal experience.

The attorney's coping attitudes, such as they are, tend also to be reinforced by his professional context, and it is perhaps no mere circumstance that the particular individual is united with the profession of law. Law has so much to do with the definition and protection of property rights, with the benefits and safeguards of status, and with protection and freedom for a variety of profit and gain motives. It promotes these ends by means of a highly conspicuous adversary process. It is stubborn and self-protective in the way in which it guards its power through the zealous operation and use of statutes, rules of procedure, and similar standards. These are all circumstances that allow possessiveness of various kinds to flourish. 


\section{Cooperation, Communication, and Conciliation}

The matter of the relation between humans is too frequently put as an issue involving mostly or only competitive and surpassive relations. The greatest concern seems to be the position of superiority or inferiority of a party and the matter of taking gain or loss from another. But the most essential quality of human relations is that they afford a sense of being that is not apart and different from others but with and like others. They enable a person to establish a sense of community and avoid the fright of alienation. In the reciprocity and mutuality of human relations, the person is assured of acceptance, belonging, and support that make his contact with reality very real, gratifying, and reassuring. On a plane of practical experience this means establishing affable and affectionate relationships, cooperative enterprises based on mutual consent, and mutual dependencies and loyalties. In these there is the touchstone for political and social groupings, and for the survival and promotion of the human species itself.

The principal behavior that sustains human relations is empathic communication. It is friendly and conciliatory behavior and may be marked by concern, helpfulness, and possibly affection. In its professional aspect, this leads to an attitude of negotiation and a desire for understanding and agreement. Its total absence may lead to a resolve to be aloof and uninvolved, to too rapid feelings of weakness or incapacity to sustain relations, or to easily developed resentment and opposition toward others.

The store of an attorney's experience preceding his professional contacts with law affects his particular attitudes in matters of human relation. His vital and formative experiences with others may lead him to require to be heard, understood, and accepted by others. $\mathrm{He}$ may assume or require warmth and understanding in dealing with others; he may experience or seek gratification in cooperative venture; he may prize the assurance of insight and information in communication. Or, if the burden of frustration in human relations has been too great, he may operate in a manner that suggests indifference to human sensitivity and impatience to develop understanding.

Once again, the offices and traditions of law and the character of some social problems with which it is involved are the means for reinforcing predispositions in human relations. The attorney may negotiate and conciliate, ostensibly for "practical" reasons of maneuver and advantage, but quite possibly for the personal gratification of resolving problems of relationship in this manner. If he becomes a virtuoso in adjusting disputes without resort to oppressive power, one 
can more certainly identify some strong sensitive and felicitous personality chords. The fields of contract negotiation and family relationships afford ample vehicles for the implementation of sensitive attitudes and dispositions about the character of human relations. The entire concept of equity, equitable remedies, and such historical equitable and legal notions as freedom from "fraud," and "equal rights" constitute particular safeguards for and an interest in the quality of human relations.

\section{Self, Independence, and Responsibility}

The sense of self, or in social and political terms, the relationship of the individual vis-à-vis society, is a volatile matter. Both social and personal history are a testament to the struggles between unique forces and general organization. In personal terms, the matter is one of striving for independence, uniqueness, and integrity. Its counterpart is the acceptance of limitation, order and regularity, and communality. The character of the blending, rather than an outright choice between alternatives, is the common issue.

The individual's struggle for independence is a large part of the history of the parent-child relation. His ultimate acceptance of a larger, external authority is the major aspect from a societal viewpoint. In the evolution of a pattern of adjustment, there is a constant juxtaposition of authority and opportunity, conformity and experiment, discipline and license, responsibility and indulgence. Through intense, life-long immersion in the processes of play, learning, and work under some quality of supervision, a person is likely to come up more or less strongly on one side or the other, accentuating individual freedom or community responsibility. The behavioral qualities that reflect continuing concern in the struggle are persistence, zeal, and aggressiveness. In their extreme-where the involvement is notably intense-behavior may become intractable, belligerent, punitive, and highly opinionated.

The presence of self in the individual attorney is largely a reflection of his success, or lack of it, in giving himself a unique identity and yet abiding by society. Extreme aggressiveness in action, extravagant dedication to rights or responsibilities, and excessive insistence on the simplification of issues in moralistic blacks and whites evidence the continuing tensions of the struggle.

Not unexpectedly, law is an accommodating and sometimes overpowering mistress for the personal dispositions of an attorney. The issue of the individual against society is most clearly seen in matters of criminal law and civil liberty; constitutional documents-notably 
bills of human rights-intensify and fortify the struggle and the drama. The adversary process serves as a battleground on which passions about the issue may be exercised. A most basic issue, in personality and society, is joined in the way an attorney uses the rules and processes of law.

\section{Change in Personality}

The implication likely is given that personality is a fixed entity while other factors are subject to change. It is fair to inquire whether personality-here the attorney's personality-is perhaps more adjustable, or more erratic and unpredictable, than previous analysis suggests.

Personality is not static. It is the product of growth and change over long stretches in the span of life. Mostly, it perseveres in its essential temper and disposition with the reasonable maturity of the individual. It is not inflexible but it is consistent. Intervening, shockinducing experiences are essential to change consistent patterns and inclinations. Systematic change or continuing evolution in personality may be anticipated mostly in early maturity, and hence in early professional life. The young attorney, for instance, may become relatively more confident, hardened, and aggressive with the accumulation of professional experience. Perhaps in later years the experienced attorney may become more philosophical and conciliatory so that his disposition to seek agreement and amicable resolution in conflict becomes stronger. Sometimes the early dispositions of an attorney may be reinforced so that, for instance, the coping attitude and the striving for possession become stronger. Or, to put it differently about another kind of attorney, "once a fighter, always a fighter."

Patterns of evolutionary change are generally slow, observable, and predictable in their development. Hence, whether there is great persistence in personality or gradual change, so long as there has been no drastic experience touching an individual's essential reactions, personality becomes an ordered, systematic, and discrete factor in the study of what moves and influences legal consultation.

Adjustive Legal Processes: Litigation, Negotiation, and Counseling

The sharp and discriminatory influences of personality are keenly felt in the adjustive processes of law: litigation, negotiation, conciliation, and counseling. The characteristics of virtue and the basis of success are different in each of these. 


\section{Litigation}

Litigation is a process that thrives upon a competitive spirit, a motive of partisan gain, and a disposition to exploit. These elements are exercised in the form of direct contest between individual attorneys and in the measure given in terms of preferences for one and against another. ${ }^{2}$

The relationship between the attorney whose primary qualities of personality are reflected in coping, competitive behavior and the litigation process is virtually symbiotic. There is a close congeniality between the psychological qualities of litigation and the attorney whose personality is marked by zealousness and aggressiveness. The attorney who takes a friendly and conciliatory attitude, assuming this to be a fixed need and propensity rather than a tactic, is most likely to find that his personality is a liability in litigation.

Evidence for the distinction is most likely to be noted in litigation in which the "instinct for the jugular" is important. The coping, competitive attorney is likely to be more assiduous in searching out the facts of his case. He will appear "better prepared," and may have discovered more elements in a case-but perhaps only because he has a greater appetite for the work. The aggressive attorney is likely to prove more thorough in courtroom examination. He is likely to probe and penetrate more effectively. He may be more effective in crossexamination-notably in the impeachment of witnesses-because he is more inclined to press for an advantage at the expense of others. The conciliatory or non-litigious attorney may be less dramatic. He may fail to crystallize issues in clear dichotomies and thereby fail to penetrate sufficiently or to impress a judge and jury. Lacking militant partisanship he may miss opportunities for tactical advantage because he takes more the overview of a judge than the grasping approach of an advocate.

The appearance of intelligence and skill in an attorney may indeed be partly a matter of personality. Differences between attorneys in personal discipline and disposition make for differences in determination, incisiveness, and perspective; these are critical matters in the outcome of litigation. Personality differences may reach even to the matter of the kinds of cases handled by attorneys. Some, as a matter of disposition, are better suited to developing the web of facts in cases involving many social or economic intricacies. Thus, the coping,

2 The author has reflected upon the psychological dimensions of the litigation process, particularly as they are experienced by litigants. See Redmount, Psychological Discontinutities in the Litigation Process, 1959 Duke L.J. 571. See also Redmount, supra note 1 . 
competitive attorney may be more "at home" with an anti-trust case. The more self-assertive attorney may probe a matter in tort or criminal law more effectively.

\section{Negotiation and Conciliation}

Negotiation and conciliation require a differently constituted personal disposition and adroitness. Lacking the limitation and the safeguard of the fixed procedure encountered in litigation, its successful use is insured by more restrained behavior by all parties. Its individual personality bulwarks are the search for some common interest, an empathic understanding of others, and a modulated sense of self that permits flexibility and a larger range of solution. These elements serve to attentuate rank partisanship where the desire is to avoid litigation. They do so fundamentally by creating a new source of control in the situation: self-subjugation. A larger consciousness of issues, purposes, and feelings is evolved and this consciousness serves to channel or eliminate the sharper competitive or aggressive dispositions.

The alignment, or misalignment, of attorneys and legal process on the basis of personality is virtually self-evident here. The empathic, conciliatory attorney finds negotiation and conciliation altogether congenial. The coping, competitive attorney may be too tenacious and hence more resistant to the needs for flexibility and self-limitation inherent in the mediational process. At the same time, his acquisitive biases may serve well in bringing to bear more considerations, albeit of a partisan nature, that may serve to amplify the situation and ultimately to enlarge the range and possibility for a basis of understanding. The zealous, aggressive attorney is perhaps most disadvantaged in the mediational process because of his relatively greater intolerances and impatience. $\mathrm{He}$ is the least inclined to develop larger insights and forebearance.

Negotiation or conciliation in the hands of aggressive attorneys takes on the character of litigation. Partisanship may become more intense and exploitation more brutal. Resolution, if any, takes the form of a forced reduction in strength or compromise of one party by the other. On the other hand, given the process in the hands of coping, competitive attorneys, there is likely to be more elaborated but interminable fact and argument. The prospect is that mediation involving an aggressive attorney as one of the participants is likely to be shortcircuited, whereas any mediational process involving a coping, competitive attorney, with no intrusion from more aggressive personalities, is likely to be protracted. Mediational processes are taxed and the 
possibility of successful outcome diminished where forebearance is lacking.

Subtlety in personality interaction is the exceptional requirement of the third party negotiator or conciliator. To avoid either authoritarianism or impotence and hence to evolve a truly mediated decision, he must encounter personal behavior from several perspectives. Cognizance of his own dispositions is paramount and provides a source of awareness and control in the mediational process. At best, he may establish rapport with the parties on the basis of a distinterested attitude toward the outcome, or an attitude of transcendent interest that suggests mutual goals beyond the immediate matter. Evidence of an empathic understanding is further reassurance to the parties that adequate communication is safeguarded. A selfless approach affords an ethical guarantee and suggests the probability of a minimum of bias. Next to his own self-awareness, the third party must perceive the personality biases evinced by the antagonists. This focuses on the sources of some potential discontinuities in the mediational process, such as the clash of markedly aggressive or avaricious motives. And finally, the third party negotiator or conciliator must produce the knowledge and subtlety of personality necessary to counter and divert aggressive and competitive dissonances, so as to build a proper foundation of temperament for successful mediation.

The distinctive effects of personality in mediational processes may be posited and perhaps measured in certain contexts of operation. It is likely that labor-management negotiation suffers from an excess of coping, competitive behavior. Negotiation is frequently protracted well beyond the period necessary for defining issues. In criminal cases, the possibilities of pre-trial compromise are severely limited. The reasons are basic to the issues in criminal processes, but in many instances they may also stem from highly polarized attitudes and intemperance on the part of the attorneys involved. Settlement in compensation matters may be notoriously difficult when the coping attitudes of the attorneys are extreme. Inelasticity and delay are likely to be more frequent than necessary in these cases because of tenacity and avarice. Amicable resolution of conflicts in family relationship and matters of estate may too frequently be stymied by belligerence and intractability - the attitudes of the parties also being reflected in the personality expression of their attorneys.

Negotiation and conciliation are matters requiring considerable personality "skill." Success usually attends the attorney whose personality is psychologically more pliable and subtle. It is a difficult process, and this is perhaps evidenced by the tendency of some media- 
tional procedures, like arbitration, to take on the temper and appearance of litigation.

\section{Legal Counseling}

Client counseling is probably the most important adjustive process in law. Problems, plans, and dispositions of a case may never reach beyond the law office. And even when they do the possibilities of a case are already largely determined.

The early definitional phase of counseling provides both the greatest ambiguity and the largest opportunity for the operation of personality influences. ${ }^{3}$ A client may appear upon the scene and be very determined, troubled, and uncertain, or perhaps fearful and defeated. Occasionally, he may appear decisive, but generally his uncertainty, fear, or ignorance of law renders him putty in an attorney's hands. $\mathrm{He}$ is to the attorney much like Kipling's celebrated elephant, who took on as many appearances as he had observers and raconteurs. In response to the ambiguity of the client's problem or his intensely frustrating experience, some attorneys may tend to focus on the elements that incite a larger sense of difference or conflict, others will more readily recognize elements that reflect a change of status in terms of gain or loss, and still others are disposed to see the reassuring elements in a problem.

An attorney who is dedicated and aggressive about the matter of personal rights and independence will be more inclined to champion his client's position. He will emphasize aspects of the case that stress the need for vigorous protection or redress. The emotional stance taken by the attorney is likely to be belligerent in behalf of his party. $\mathrm{He}$ is prone to litigate the matter-most matters, in fact.

Another attorney may more naturally tend to see clients' problems as issues of status, solvency, or profit. Frequently, he thinks of and puts a case as a matter of cold economics. The goal of his strategy is to preserve and increase his client's material resources. $\mathrm{He}$ is more likely to relate to his client as a planner than as a champion. His defenses for his client are more dogged and detailed than they are dramatic or belligerent. His use of any forum, litigious or otherwise, is more strategic than inevitable. His approach is probably the most common, both because of the realities with which the attorney usually deals and because his is a commonplace bias in the profession.

A third kind of attorney tends to perceive his client's problems in terms of the possibilities for offering large measures of immediate

3 This aspect of legal counseling, as well as some others, have been analyzed by the author in the context of counseling on a matter of divorce. See Redmount, Perception and Strategy in Divorce Counseling, 34 ConN. B.J. 249 (1960). 
comfort and reassurance to the client, however biased the latter's view of reality for the moment. The attorney directs his efforts to breaching conflict and conciliating differences. He seeks to stabilize feelings and arrangements among the parties as a true expression of their needs and interests. $\mathrm{He}$ is likely to abhor litigation and ignore elements that would promote militant partisanship in others. He may even apply personal pressures to coerce individuals into agreement.

\section{Circumstances That Control the Influence of Attorney Personality}

Surely, it is not personality alone that is decisive in the counseling of clients. In fact, adequate perspective requires that the circumstances presented by a client be given their weight, and these frequently determine the path of counseling. A man charged with murder requires only that an attorney fix the course of litigation as much in his favor as possible. There is limited room for choice in the attorney's perceptions and decisions in the matter. A client who consults an attorney for articles of incorporation in order to establish a new enterprise also contemplates the attorney in a ministerial capacity. The attorney's perception is narrowed by circumstance, for it is his technical skill rather than his global judgment that is required in the situation. The empirical issues are so specific that the vicarious operations of personality are given no opportunity to mold or distort them. Should the attorney seek to control empirical circumstances so that he can consistently respond to certain known inclinations in his personality, he does this most effectively by limiting the range of his practice. He may limit himself, for example, to matters of taxation and corporate organization, to the practice of criminal law, or to problems of labor relations.

Moreover, the personality dispositions of attorneys operate only when there is ambiguity in a client's situation or when complexity affords more than one mode of operation in simplifying the matter. For instance, personal disposition is likely to be a factor in a dispute between a contractor and a client in which the issues may be molded in such a way as to permit resolution by either litigation, drawing new articles of agreement, or arbitrating differences. Accident cases usually permit either litigation or settlement, and the attorney's temperament may be a decisive influence in the choice. A matter of divorce may involve many issues and a choice in handling them: some attorneys may muster the circumstances so that litigation appears inevitable; others assemble the case so that the issue is presented in terms of a need or desirability of conciliation; and yet other attorneys may tone down the litigious aspect, perfunctorily consider and then discard the prospect of conciliation, and finally concentrate on drawing 
up articles of agreement regarding property settlement, custody, and the like.

\section{Preemptive Versus Empathic Legal Counseling}

Frequently, when the client's case is neither clear nor highly specific, the client's appraisal of the "legal situation" and of possible action is a process of fortifying the outlook taken by the attorney. By gradually, consistently, and reciprocally reinforcing both his own and the client's perceptions and thought-by the mostly unconscious operation of his own personality-the attorney generally arrives at a fairly fixed position in handling the matter. In such a situation there is characteristically little room for any extended communication between attorney and client about perceptions and strategy. The client, unless his attitude is exceptionally strong, stands aside. The attorney, having instructed rather than counseled with the client, proceeds in a determined manner with little doubt as to the correct perception of his client's feelings and problem, and as to the choice of strategy.

Properly, one might characterize this process as preemptive legal counseling, and it may well be the client who is served with the preemption. To explain, one might consider the dissolution of a business partnership in which the partners cannot themselves agree on the terms of dissolution. They agreeably decide to turn the matter over to an attorney. The matter is presented to an attorney by one of the partners as an issue of planning and negotiation to arrive at the specified enddissolution. The psychological disposition, however, is not firm but tentative. This individual would prefer the continuation of the relationship if an amicable agreement cannot be reached, for reasons pertinent to some other involvement with his partner. However, he himself has not yet recognized the risks entailed for friendship in working at the issues of dissolution, and he presses concertedly for the latter. Once the seeds of discord are sown, he jeopardizes the good will of the other party.

A preemptive counseling approach recognizes observed or stated facts from and about a client. The client's attitudes, and perhaps his more basic aspirations, are not fully and sensitively explored. In one instance, the comparatively impatient, litigation-prone attorney embroils his client in harsh struggle-perhaps ultimately in unnecessary and undesirable litigation. Another coping, competitive attorney may make too much of the economic arrangements for dissolution. In a business sense he may have resolved the matter, but he still may not have served the client according to the latter's needs. A non-preemptive attorney who truly counsels with the client and takes the time to ex- 
plore in greater depth the client's circumstances and attitudes will have produced a more harmonizing result. It serves neither the client nor economy in the use of formal legal procedures to say that the attorney should eschew empathic legal counseling.

The attorney, as it thus appears, ought not be a mere catalyst for his client's views, opinions, and preferences. Consciously or unconsciously, he asserts through his personality social and legal policy that is at least in some part a reflection of his own values and dispositions. If he is sufficiently conscious of the major trends and influences operating within him, his choice is at least by direction. He may be able to choose the degree to which he will bear personal influence on a given situation. If he lacks consciousness of the biases in his personality and does not detect their operation, he introduces unnecessary rigidity in dealing with his client's problems. What appears as rational disposition of a matter may be but camouflage for fixed attitudes that offer no alternatives to clients and limit the range of possibility in achieving desirable solutions to clients' problems.

\section{Personality and the Sequence of Critical Decisions in Legal Consultation}

One can identify a series of critical points of choice in legal consultation. First, there is the moment when the attorney and his prospective client first confront one another and the attorney, particularly, draws his impressions. Next, there is the time when the client, with or without the attorney's aid, finally delivers himself of a comprehensible and coherent cause. Then, there is the moment that the attorney sets his strategy for serving his client. Critical decisions are also made when an attorney first approaches the other side, and again when the tenor of the latter's reply in negotiation transpires. Then there is the moment when a decision is made to exploit or reduce negotiation to some more advanced stage of outcome.

Attorney personality at each of these choice-points in legal consultation is likely to forge a consistent strategy. It is usually directed to a particular solution and structures decision perhaps as much as the rational determinants that coalesce under the labels "fact" and "theory." One can observe and assess the process by focusing on the interaction between specific attorney personalities and their attitudes, and decisions at the critical points in consultation. The likeliest combinations will find the more zealous, combative attorney making short shrift of his client's matter as he guides it through the inexorable course of litigation; the coping, possessive attorney buttressing data and argument in an effort to forge a partisan advantage that will bring 
a substantial return at any point before, up to, or including litigation; and the conciliatory attorney seeking, both for his client and himself, a better understanding of his client's feelings and of the circumstances and equities of the situation in order to render a noncombative course of action and decision.

One may project a case in point.

An outspoken, demanding, rather impatient person comes to an attorney with an ired plea. He has reason to believe that his remainder interest in a trust is being decimated by the trustee's imprudence. Construing the trust instrument as containing a permissive authority, the trustee has converted holdings with a low income yield to invest in a more risky venture which promises a higher income for the life beneficiary but no increase in the value of the remainder. The irate complainant argues that the trustee has exceeded his authority. He seeks to force the trustee to return to prior policies; and he would remove and replace the trustee.

It is not unlikely that the more belligerent attorney would be receptive to his client's attitude without need for inquiry or further reassurance. It directly facilitates and encourages what in his view is the essence of legal service-litigation. The crucial facts for him may be an ambiguity of the trust instrument which permits an interpretation in his client's favor, evidence that the trustee has grossly manipulated trust property interests, and the effect that the value of the trust res is questionably jeopardized. Progressing almost as if by nature, the attorney moves toward uncompromising victory. His client's clear and facilitating attitude and the facts of the case are convincing of both need and prospect for vanquishing the trustee. In the stab at negotiation, the attorney perceives that the trustee's counsel upholds the trustee's discretion and makes sense of the latter's decision. This counsel is not disposed to view the matter in the sharp perspective of the aggressive attorney, and he seems unlikely to submit. In fact, the aggressive attorney's proposal that the trustee abandon his position is met by a counter-proposal that the trustee work out an equitable arrangement pleasing to both beneficiaries. At each juncture in the evolution of the matter the aggressive attorney adds fuel to his determined view of the case. Resistance by opposing counsel and the latter's offer for a mutual adjustment (retreat) merely reaffirm the need to eliminate opposition. There seems neither point nor promise in any further negotiation since clearly litigation is best designed to force the desired result.

The more acquisitive attorney may find the client's ire tolerable, even if it is not congenial. It merely seems to indicate a more intense 
coping and possessive demand than is the real focus of the attorney's interest. He, having found a common basis of interest and relation with the client, now seeks to "get down to the facts." He may be struck more by the ambiguity than by the license afforded in the terms of the trust as they apply to the powers of the trustee. He may examine the trustee's policies and the investment risks more carefully in order to ascertain whether his client's interests are perhaps better protected than impression suggests. He may see alternatives to the trustee's investment decisions, perhaps in reconverting holdings to a line of investment in which there is less risk to his client's interest but slightly improved income return. He may find it desirable to negotiate in order to put his client in a better position. His strategy is to project a cautioning attitude toward the trustee and to redirect some investment policy. In negotiation, the acquisitive attorney may find any attitude short of outright intransigence useful as a bargaining lever. He is likely to perceive a defense of the trustee's action, and a counter-proposal to suspend action pending some further inkling of the effects of the trustee's moves, as substance from which to try to draw additional arguments. He forebears from litigation, at least until there seems to be an impasse in which his client's interest is threatened. He gains for his client the apparent substance of the latter's desire-a safeguarded economic position-but possibly not the emotional release attendant upon the trustee's dismissal which the client's aroused feelings demand.

The conciliatory attorney is likely to be impressed at once by his client's distended feeling and to view it inquisitively. If he finds the client's attitudes and behavior intractable and unreasonable, he might foreclose further strategy and involvement by deciding that he is not the person to work with the case. Quite possibly, he would not do so but would pursue the case perfunctorily-substantially in the same direction as the aggressive attorney, but without the zeal that affords reassurance and determination. More often, he would think it worthwhile to probe the client's attitude. Molding patience and scepticism, he might develop another line of factual inquiry by which he discovers that his client fears what he regards as the trustee's personal animosity toward him based upon previous relationship. The client thinks the trustee intends to deprive him of his interest. On the other hand, the attorney might discover that his client is not opposed to some speculation with his interest, but regards the particular investment as unwise. Perhaps the trustee is unaware of some facts about the new investment which are known to the client. Because of their strained relation, the client has seen no possibility to influence the 
trustee and has been otherwise disinclined to further personal association with the trustee. Seeing the sources of disturbed relations, the conciliatory attorney reinforces his inclination to resolve differences amicably by choosing clarification of feeling through negotiation as the proper strategy and goal. Entering negotiation he has little difficulty with the attitude of his opposite number because of his disarming attitude and reassurance that all parties can be served by clarifying feelings and exchanging information. Proposals by the trustee's counsel may be viewed as a means toward further amicable relations and an opportunity for extending the clarification process rather than as an obstacle to agreement. The outcome of negotiation is usually clearly directed toward the elimination of strong outstanding differences and litigation is likely to be resisted by the conciliatory attorney.

Consistency in the sequence of decision in legal consultation may not be as easy and clear as the "pure" aggressive, acquisitive, and conciliatory approaches suggest. An aggressive attorney may become quite conciliatory in negotiation if the proper approach is made to him. The acquisitive attorney may be unconsciously irritated by his client's aggressiveness so that he lets the conflict follow a natural course toward combat and litigation. A conciliatory attorney may feel he should take a litigious view if it surely serves to protect his client's interests, even though his client might be reconciled in other ways. The combination of possibilities is fascinating to consider. However, the essential matter is that understanding and predictability in the handling of legal consultation can be developed. It requires careful study of the relation between attorneys' personalities and other factors at several critical stages in the evolution of the consultation process.

\section{Some JuRisprudential Implications}

A more studied concern for the consultative processes in law stimulates some important observations. If consultative processes are properly handled, the need for law in its formal aspect, particularly trial and appellate procedures, is frequently obviated. ${ }^{4}$ The attorney and the attorney's work thereby become not merely catalytic or ancillary to a legal proceeding but, in fact, the whole of the legal operation. ${ }^{5}$ The

4 This is the essential premise in Brown's "preventive law." He argues for and diagrams a fuller fact discovery and a broader and more imaginative choice of legal strategies in helping clients achieve satisfaction and protecting them from avoidable litigation. See Brown, The Law Office-A Preventive Law Laboratory, 104 U. PA. L. Rev. 940 (1956); Brown, Legal Autopsy, 39 J. AM. Jun. Soc'y 47 (1955).

5 "[A] great deal of the law under which all of us live . . is written ... by American lawyers, sitting in their offices, striving to carry out the lawful wishes of their clients." Cavers, Legal Education and Lazeyer-Made Law, 54 W. VA. L. Rev. 177, 178-79 (1952). 
attorney's judgments and tactics have the significance of a formal legal prescription or a legal finding, at least as to the parties involved. To comprehend his attitudes and operations is to develop significant purpose and meaning in law.

Jurisprudential inquiry of this sort is oriented toward personal psychological and social experience. The principal concern is for the resolution of personal frustrations and conflicts, with the emphasis being as much upon social and psychological considerations as upon political, ethical, and economic considerations. The measure of success is the most satisfaction and the largest sense of well-being which parties may achieve without a residual of intolerable frustration or pain to any one. In this kind of solution rests the true basis for maximizing the accommodation of individual behavior to a social order. In respect to social order, this kind of process and solution proves its worth more than strict adherence to political, economic, or ethical considerations alone. There is no need for a losing party to eat crow or a winning party to be so thwarted by delay and the kind of gratification he receives that he is unrequited. There is less need to resist, protest, or to take it upon oneself to change or reverse the legal outcome. There is more nearly an ideal harmony between individual needs and social order.

The attorney, by providing for the largest measure of fulfillment, buttresses the strength and importance of law. He does so without taxing litigation resources and thereby sharpening aggressive feelings. Litigation and the testing of legal norms is more nearly reserved for instances in which a clear corrective or educational aim is warranted in order to preserve basic social values that have been severely violated and need to be dramatically stressed.

The thrust of this thinking is that "unofficial" as well as "official" law needs to be developed and understood. ${ }^{8}$ It is reasonably discreet in its operations, significance, and effects. Although it is "official"

6 The emphasis here is primarily on the decision-making aspect of "unofficial" law. The matter of developing an attorney's skills in legal consultation ("unofficial law") has long been the subject of much discussion among legal practitioners and educators. Currently, Professor Rutter has reduced the discussion to a fixed instructional program-perhaps the most extended systematic effort to encompass "unofficial law" from the standpoint of the range of insight and technique essential to legal consultation. See Rutter, $A$ Jurisprudence of Lazeyers Operations, $13 \mathrm{~J}$. LEGAI ED. 301 (1961). Cf. Sacks, Human-Relations in Training for Law Students antd Lawyers, 11 J. LEGAI ED. 316 (1959). Professor Sacks is concerned with devising a training approach to help law students develop interpersonal skills in interviewing, counselling, and negotiating. Cf. Lasswell \& McDougal, Legal Edncation and Public Policy: Professional Training in the Public Interest, 52 YALE L.J. 203 (1943).

The author has presented something of an incorporative, psychologically-oriented framework for the consideration of both "official" and "unofficial" legal processes. See Redmount, The Relation of Laze and Psychology, in LEGAL AND CRIMINAL Psychology 22 (Toch ed. to be published Aug. 25, 1961). 
law that has characteristically engaged interest, and the attorney's work has been subordinated, there may be more of a coordinate or complementary rather than a hierarchic relationship between judgemade law, legislation, and attorney consultation. At the least, this is true on the practical level of individual and social experience. Here, official decisions, rulings, and statutes serve as reasonably flexible guides, whereas in their more symbolic and abstract function they may have to be considered as rigid proscriptions and directions. In most instances they are important elements rather than fixed determinants of concrete experience. It is important that they be so, and that they do not throttle common experience by equating the practical and the real with the ideal. Adequate attorney consultation is more suited to this purpose than a watered-down litigation or legislative process that turns its head while its formal operation is crassly manipulated to produce practical results.

The idea of a largely unyielding and inflexible certainty and order in law is an untenable premise. It is not true as a practicality and not desirable as an ideal. Or, to be more accurate, it is only partially true and desirable. Many other values than the ethical need to be stressed, not merely tolerated. Traditional legal concepts of equity operating at a judicial level and post-dated remedial legislation do not adequately meet the range of demand and expectation posed to both the attorney and the law when a concrete personal frustration and social conflict is presented. At the point where the tenets and operations of law meet with practical experience there must be an inordinate sensitivity and immense flexibility attuned to social experience. It is here that attorney consultation ought to take its place as a pillar of both law and society. 